\title{
Case Report of Peritoneal Hydatidosis Diagnosed as Ovarian Cyst
}

\author{
Narinder Kaur, a,c Buddhi Kumar Shrestha, ,c, Subha Shrestha, ${ }^{\mathrm{a}, \mathrm{c}}$ Nabin Pokharel ${ }^{\mathrm{b}, \mathrm{d}}$
}

\begin{abstract}
:
Primary peritoneal hydatidosis is a rare condition and it was mistiaken for ovarian cyst. Hydatid disease is caused by dog tape worm, Echinococcus granulosus, and is the commonest one having worldwide distribution. Human hydatid disease results from infection with larval form of Echinococcus granulosus. The disseminated intra-peritoneal hydatid disease is a rare finding. A case of disseminated intra-abdominal hydatid disease is presented along with a review of literature and various therapeutic modalities.
\end{abstract}

Keywords: disseminated $\bullet$ hydatid cyst $\bullet$ peritoneal hydatidosis

\section{INTRODUCTION:}

Peritoneal hydatidosis is an uncommon finding. Secondary peritoneal hydatidosis is more common than primary. Secondary cases are commonly associated with hepatic hydatid cysts. Only a few cases of primary peritoneal hydatidosis have been reported in the literature till date. In this report, we review seven cases of peritoneal hydatidosis of which one is a case of primary disseminated peritoneal hydatidosis while the rest are secondary to hepatic and / or splenic lesions.

\section{CASE REPORT:}

Mrs. XYZ, 28 years old women admitted with complains of progressive enlargement of

a - Lecturer

b - Assistant Professor

c - Department of Gynecology and Obstetrics

Lumbini Medical College Teaching Hospital, Palpa, Nepal

d - Department of Surgery

Lumbini Medical College Teaching Hospital, Palpa, Nepal

Corresponding Author:

Dr. Narinder Kaur

e-mail: nkaur@jlmc.edu.np

How to cite this article:

Kaur N, Shrestha BK, Shrestha S, Pokharel N. Case report of peritoneal hydatidosis diagnosed as ovarian cyst. Journal of Lumbini Medical College. 2013;1(2):118-9. doi:10.22502/jlmc.v1i2.34. abdomen associated with pain. Her main complain was pain in abdomen of one month duration. She was average built sick looking woman. Her general parameters were within normal limits. On abdominal examination, abdomen was soft. There was a cystic mass about $15 \mathrm{~cm} \times 15 \mathrm{~cm}$ in right iliac region. It was mobile and tender. There was no evidence of free fluid in peritoneal cavity. On local examination, cervix and vaginal were normal and healthy. Uterus was of normal size. Left fornix was free. In right fronix, same mass was felt which was tender with restricted mobility.

Clinical features were suggestive of twisted with imminent rupture of ovarian cyst. Her blood pressure, urine analysis, hepatic and renal function test were normal. ECG was within normal limit. Chest X-ray was normal. Ultrasonography showed a mass of mixed echogenicity and right ovary was not visualized.

Laparotomoy was done. The operative findings were: uterus, tubes and ovaries on both sides were normal. There was no free fluid in peritoneal cavity. There was a cystic mass having adhesion with small intestine and rectum. The adhesions were separated and cyst was removed completely. There was no communication with any organ. Peritoneal cavity lavage was done with 
hypertonic saline. There ware no daughter cysts and abdomen was closed in layers. Oral albendazole 400 mg daily started from the second post operative day. Recovery was uneventful. Patient was discharged on $7^{\text {th }}$ postoperative day with advice to take albendazole $400 \mathrm{mg}$ daily for four to six months. On follow up, she reported once in OPD. She is fine and fit and continuing albendazole treatment.

\section{DISCUSSION:}

Hydatid disease is endemic in many parts of the world, where there is a close association of humans with dogs, the definitive host. Liver (55$75 \%)$ and lungs (18-35\%) are the most commonly affected sites. Studies have shown that peritoneal hydatidoisis is rare. It is usually secondary to heptic, splenic and mesenteric cyst or having concomitant to liver and retroperitoneal hydatidosis. ${ }^{1,2}$

The infection is usually acquired in childhood and remains asymptomatic until the adulthood. Symptoms of cyst depend on its localization, pressure effect on the surrounding structures and rupture of cyst. Abdominal pain is the most common complain. Followed by pressure effect like nausea, weight loss and breathlessnss on exertion and orthopnea. ${ }^{2,3}$

In our case, woman came with lump in abdomen associated with pain. Ultrasonography is the investigation of choice in the case; the clinical findings were suggestive of ovarian cyst of mixed echogenicity. Ovary on the right side could not be visualized.

The treatment of choice is surgical and complete removal. Unroofing and drainage of cyst is safe alternative if the pericyst is adherent to surrounding structure. ${ }^{1-4}$

\section{CONCLUSION:}

Primary pertoneal hydatidosis is a rare entity but always to be kept as differential diagnosis in case of lump in abdomen in endemic areas. Ultrasonography is helpful in diagnosis and follow up of the case. Definitive treatment is surgery. Albendazole prevents the recurrence and should be given as a long term treatment.

\section{REFERENCES:}

1. Blumgart LH. Surgery of the liver, biliary tract and pancreas. Vol 2, 4th ed, WB Saunders, Philadelphia, 2007.

2. Chowdhury G, Singh N. Huge peritoneal hydatidosis mimicking ovarian cyst of India. J Obstet Gynecol India. 2012;62(2):194-4.
3. Mosca F, Portable TR, Persi A. Uncommon abdominal sites of Hydatid disease, our experience with surgical treatment of fifteen cases. Chir Ital. 2006;56:333-44.

4. Nadeem N, Khan H, Fatimi S. Giant multiple intraabdominal Hydatid cyst. J Ayub Med Coll Abbotabad. 2006;18:70-1. 